\title{
Saccharomyces SRP RNA secondary structures: A conserved S-domain and extended Alu-domain
}

\author{
ROB W. VAN NUES and JEREMY D. BROWN \\ School of Cell and Molecular Biosciences, The Medical School, University of Newcastle, Newcastle Upon Tyne, NE2 4HH, UK
}

\begin{abstract}
The contribution made by the RNA component of signal recognition particle (SRP) to its function in protein targeting is poorly understood. We have generated a complete secondary structure for Saccharomyces cerevisiae SRP RNA, scR1. The structure conforms to that of other eukaryotic SRP RNAs. It is rod-shaped with, at opposite ends, binding sites for proteins required for the SRP functions of signal sequence recognition (S-domain) and translational elongation arrest (Alu-domain). Micrococcal nuclease digestion of purified $S$. cerevisiae SRP separated the S-domain of the RNA from the Alu-domain as a discrete fragment. The Alu-domain resolved into several stable fragments indicating a compact structure. Comparison of scR1 with SRP RNAs of five yeast species related to $S$. cerevisiae revealed the $S$-domain to be the most conserved region of the RNA. Extending data from nuclease digestion with phylogenetic comparison, we built the secondary structure model for scR1. The Alu-domain contains large extensions, including a sequence with hallmarks of an expansion segment. Evolutionarily conserved bases are placed in the Alu- and S-domains as in other SRP RNAs, the exception being an unusual $\mathrm{GU}_{4} \mathrm{~A}$ loop closing the helix onto which the signal sequence binding Srp54p assembles (domain IV). Surprisingly, several mutations within the predicted Srp54p binding site failed to disrupt SRP function in vivo. However, the strength of the Srp54p-scR1 and, to a lesser extent, Sec65p-scR1 interaction was decreased in these mutant particles. The availability of a secondary structure for scR1 will facilitate interpretation of data from genetic analysis of the RNA.
\end{abstract}

Keywords: SRP; scR1; structure; phylogenetic

\section{INTRODUCTION}

Protein targeting to the endoplasmic reticulum (ER) in eukaryotes and cell membrane in prokaryotes is catalyzed by the evolutionarily conserved signal recognition particle (SRP; Bui and Strub 1999; Keenan et al. 2001). SRP binds ribosomes and nascent hydrophobic signal sequences at the $\mathrm{N}$ terminus of proteins destined for secretion or membrane integration. Eukaryotic SRP also slows the rate of translation (elongation arrest) when ribosome bound (Wolin and Walter 1989; Mason et al. 2000). SRP-bound ribosomenascent-chain complexes interact with the ER-localized SRP receptor. This leads to docking of the targeted ribosomes onto the translocation machinery. The nascent proteins are then integrated into or translocated across the membrane cotranslationally.

Reprint requests to: Jeremy D. Brown, School of Cell and Molecular Biosciences, The Medical School, University of Newcastle, Newcastle Upon Tyne, NE2 4HH, UK; e-mail: Jeremy.Brown@ncl.ac.uk; fax: 44-191-2227424.

Article and publication are at http://www.rnajournal.org/cgi/doi/ 10.1261/rna.5137904.
SRP is a ribonucleoprotein (RNP). The simplest SRP RNP is found in Escherichia coli and comprises the signal sequence binding GTPase Ffh (SRP54) and 4.5S RNA. 4.5S forms a hairpin with two internal loops toward the tip, one symmetric, the other asymmetric (see Fig. 5C below), that contain bases characteristic of all SRP RNAs. In the 4.5S-ffh complex, the loops contribute to the helical structure of the RNA and provide much of the Ffh binding site (Batey et al. 2000). 4.5S plays crucial roles in targeting: It has been proposed to form part of the signal sequence binding pocket (Batey et al. 2000) and is crucial for productive interaction between the SRP and its receptor (FtsY; Peluso et al. 2000; Jagath et al. 2001). Thus, like RNA components of other RNPs, the SRP RNA has a functional role.

Archaebacterial and eukaryotic SRP RNAs contain a second hairpin (domain III) $5^{\prime}$ to the one to which SRP54 is bound (domain IV). The SRP19 protein binds the tips of domains III and IV, aligning them in parallel (Hainzl et al. 2002; Kuglstatter et al. 2002; Oubridge et al. 2002). In most cases, this preorganization is required before SRP54 will bind the RNA. Mammalian SRP also contains the SRP68/72 and SRP9/14 heterodimers. SRP68/72 binds nucleotides 
around the junction of domains III and IV and adjacent $5^{\prime}$ and $3^{\prime}$ RNA sequences that form domain II (Siegel and Walter 1988). Domains II-IV, and the proteins bound to it, comprise the nuclease resistant S-domain of SRP (Gundelfinger et al. 1983; Siegel and Walter 1986). The $5^{\prime}$ - and $3^{\prime}$-ends of SRP RNA come together to make domain I, thereby completing a rod-shaped structure (Andrews et al. 1987; Rosenblad et al. 2003). Domain I, also called the Alu-domain (Ullu et al. 1982), associates with SRP9/14, and this part of SRP harbors the elongation arrest function of the particle (Siegel and Walter 1986).

To provide genetic insight into SRP functions, we, and others, have turned to the yeast Saccharomyces cerevisiae. The yeast SRP contains homologs of five of the mammalian SRP proteins (Srp72p, 68p, 54p, Sec65p [SRP19], and Srp14p). In place of SRP9/14, the yeast SRP Alu-domain contains a homodimer of Srp14p (Strub et al. 1999; Mason et al. 2000) and Srp21p, an SRP9-related protein (Brown et al. 1994; L.F. Ciufo, C. Blackwell, R.W. van Nues, and J.D. Brown, unpubl.). Functions of the SRP, including elongation arrest (Mason et al. 2000), are conserved to yeast. A major deficiency in understanding the yeast SRP has been lack of an experimentally determined secondary structure for its RNA, scR1 (Felici et al. 1989). Without this, the organization of the particle cannot be fully understood and, likewise, data from genetic studies on scR1 cannot be interpreted. Like several other yeast RNAs, for example, U3 snoRNA and U1 and U2 snRNAs (Ares 1986; Hughes et al. 1987; Siliciano et al. 1987), scR1 is much larger (522 nt) than its counterparts in other eukaryotes $(\sim 300)$. This large size and the small number of conserved bases in SRP RNAs have precluded alignment of scR1 with other SRP RNAs (Rosenblad et al. 2003).

A structure for the Alu-domain of scR1 has been proposed, and a putative domain IV modeled (Althoff et al. 1994; Strub et al. 1999). We have now developed an internally consistent model for the whole of scR1 combining data from enzymatic probing, mutagenesis, and phylogenetic comparison (Figs. 2A, 9A below). ScR1 forms an extended rod-like structure with similar conserved motifs to those in other SRP RNAs. The large size of scR1 is mainly accounted for by expansions to the Alu-domain, not seen in other SRP RNAs.

\section{RESULTS}

\section{Micrococcal nuclease reveals stable fragments of scR1 and regions protected by Srp54p and Sec65p}

Previously, we purified intact, active SRP from yeast cells expressing protein A-tagged Srp72p (Mason et al. 2000). Here we used the same protocol to purify SRP from a yeast strain in which all of its components were overexpressed from high-copy-number plasmids (Fig. 1; Materials and Methods). This resulted in a 5-10-fold greater yield of SRP



FIGURE 1. Yeast SRP was purified as described (Materials and Methods) from strains overexpressing either the complete particle, SRP $\Delta 54$, or SRP $\Delta 54 \Delta 65$. Approximately $5 \mu \mathrm{g}$ of purified material was either run on a $12 \%$ SDS-polyacrylamide gel and stained with Coomassie blue $(A)$ or RNA extracted from it run on a $6 \%$ polyacrylamide $8 \mathrm{M}$ urea gel and stained with ethidium bromide $(B)$.

than when the purification was carried out from cells expressing endogenous levels of SRP (data not shown), thus facilitating isolation of material for in vitro experiments. Sucrose gradient sedimentation of purified SRP confirmed that subunits remained associated through the purification (data not shown). Our approach is similar to that of Willer et al. (2003), who demonstrated that cytoplasmic extracts generated from a yeast strain overexpressing all SRP subunits have increased capacity to target substrates to endoplasmic reticulum membranes in vitro, indicating an increased level of active SRP.

We treated purified SRP with micrococcal nuclease. This enzyme preferentially targets single-stranded and unstructured regions (Rushinsky et al. 1962). Thus, it can be used to define structurally stable and/or protein-bound regions within an RNA as they are more resistant to digestion. RNA isolated from the reactions was resolved on polyacrylamide gels (Materials and Methods), and ethidium bromide staining revealed several fragments that remained during digestion (Fig. 2C, left panel). Northern blots of this and similar gels were hybridized sequentially to probes specific for different regions of the RNA. This allowed us to define the regions of the RNA from which fragments were derived, and the approximate positions of sites cleaved by the enzyme (Figs. 2C, 3A, lower panels).

At early time points of nuclease treatment, stable fragments were released from both ends of the RNA. Fragments of $\sim 90, \sim 60$, and $\sim 30 \mathrm{nt}$ (Fig. 2C, panels 30-11, 62-42, 8262) were released from the $5^{\prime}$-end, whereas fragments of 70 and $45 \mathrm{nt}$ (panels 480-461 and 522-498) were detected with 3 '-end-specific probes. These results indicate that these regions of the RNA are in highly structured domains. After longer time points of digestion, an $\sim 170$-nt fragment of scR1 was revealed (Fig. 2A, left panel). This "core" fragment hybridized to probes spanning the central portion of the RNA (Fig. 2C, panels 297-279, 394-302; Fig. 3A, panels 




Alu- domain S-domain

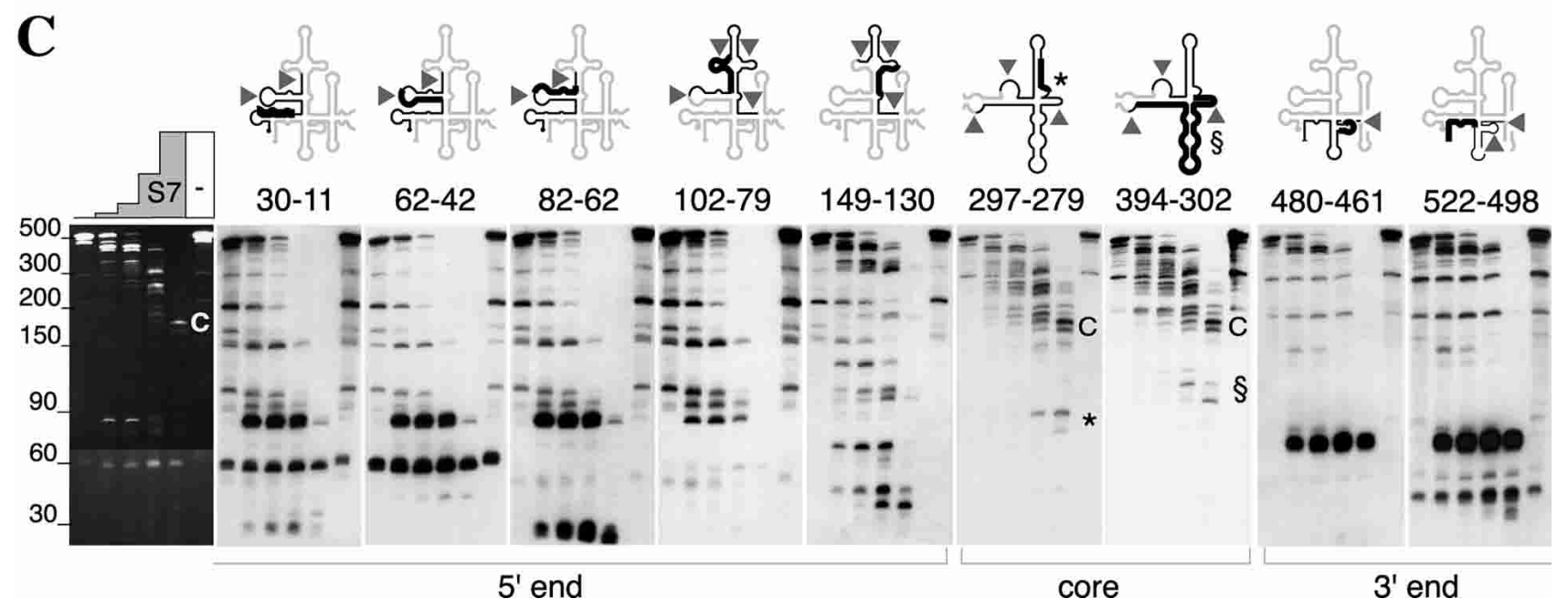

FIGURE 2. (A) Outline structure of scR1. Domains I-IV are indicated, along with regions A-F of domain I (see text and Fig. 9A for detailed model). The vertical line separates Alu- and S-domains; gray regions indicate primary sequence conservation between SCR1 homologs analyzed herein. Evolutionarily conserved bases are shown as dots within circles, those not conserved in S. cerevisiae by filled circles. $(B)$ Alternate view of the S-domain (Kuglstatter et al. 2002; Oubridge et al. 2002) used in Figures 5 and 6A. (C) Micrococcal nuclease digestion of scR1. RNA extracted from purified yeast SRP treated with micrococcal nuclease for $0,3,10,30$, or $60 \mathrm{~min}$ and a no nuclease control (indicated by stepped bars) was separated on a $6 \%$ polyacrylamide $8 \mathrm{M}$ urea gel and stained with ethidium bromide (left panel). The gel was blotted and hybridized to oligonucleotide probes complementary to scR1 nucleotides listed above each panel. Probe 394-302 was a PCR product. Cartoons above each panel illustrate approximate cleavage sites (arrowheads) as dictated by probe positions (thick lines) and major fragment sizes (black lines) in the context of the surrounding scR1 structure (gray), which corresponds to the model in $A$. $\left(\mathrm{C},{ }^{\star}, \S\right)$ The 170 -base core scR1 fragment and the $5^{\prime}$ and $3^{\prime}$ portions derived from it, respectively.

244-223, 394-375, lower panels). Concomitant with the appearance of the core fragment, smaller fragments about half this size were generated. These hybridized to probes ranging either from nt 223-315 or from 296-394, indicating partial cleavage of the core fragment between nt 310 and 320 (Fig. 3A, cf. lower panels 244-223 and 315-296 with 394-302 and 394-375). By analogy with mammalian SRP, within which the S-domain is nuclease resistant (Gundelfinger et al. 1983 ), the $\sim 170$-base fragment of scR1 may represent the S-domain of this SRP RNA.

SRP is not essential in yeast (Hann and Walter 1991), and cells lacking Srp54p or Sec65p assemble stable but incomplete SRP without Srp54p (SRP $\Delta 54)$ or Srp54p and Sec65p (SRP $\Delta 54 \Delta 65$ ), respectively (Brown et al. 1994). We therefore purified these particles from strains overexpressing all SRP subunits except Srp54p, or Srp54p and Sec65p (Fig. 1), and subjected them to similar micrococcal nuclease treat- ment as the intact particle (Fig. 3A, upper panels; Fig. 3B; data not shown).

Fragments derived from the $5^{\prime}$ - and $3^{\prime}$-ends of scR1 were produced with similar kinetics from SRP $\Delta 54$ as from complete SRP. However, neither the core fragment nor its two halves were detected. Instead, one or more novel, early cleavages were indicated by the rapid appearance of two short-lived species of $\sim 350$ and $\sim 150$ nt. Probe 394-302 hybridized to both fragments, whereas probe 315-296 bound only the larger $5^{\prime}$ fragment, and probe 394-375 bound the smaller $3^{\prime}$ fragment (Fig. 3A, upper panels). These results placed the novel cleavage site between nt 394 and 315 . The specific accessibility of these bases to nuclease digestion in the absence of Srp54p provides strong evidence for Srp54p binding to scR1 within this region. The short half-life of the fragments indicated rapid degradation of regions surrounding the initial cleavage site(s). 
A

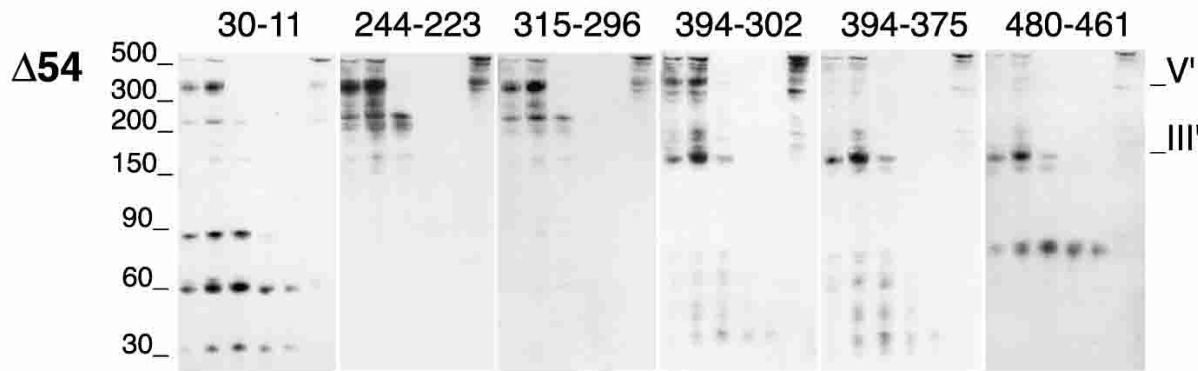

WT

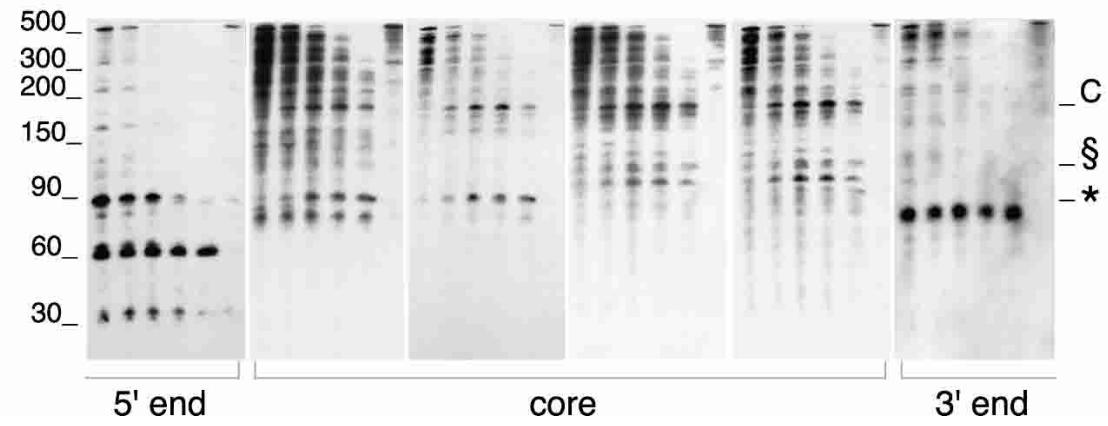

B


C

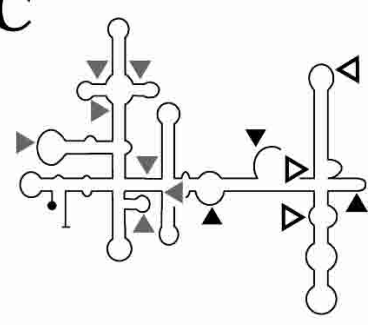

FIGURE 3. Micrococcal nuclease digestion of SRP $\Delta 54$ and SRP $\Delta 54 \Delta 65$. Similar experiments to that shown in Figure 2C, incorporating SRP, SRP $\Delta 54(A, B)$ and SRP $\Delta 54 \Delta 65(B)$. Oligonucleotides are denoted as in Figure 2C. (A) Lanes are 5-, 10-, 30-, 60-, and 120-min digestions and a mock-incubated sample; $(B)$ lanes are 5-, 30-, and 60-min digestions. Only the part of the autoradiogram referred to in the text is shown for B. Cartoons are similar to Figure 2C. Gray, black, and white filled arrowheads refer to cleavages seen in all cases, in wild type only or SRP $\Delta 54$ and/or SRP $\Delta 54 \Delta 65$ only. $\left(\mathrm{C},{ }^{*}, \S\right)$ As in Figure 2; $\left(\mathrm{V}^{\prime}\right.$ and $\left.\mathrm{III}^{\prime}\right)$ the $5^{\prime}$ and $3^{\prime}$ fragments of scR1 generated in the absence of Srp54p, (\&) the fragments generated specifically in the absence of Sec65p; see text for details. $(C)$ Overview of results from Figures $2 \mathrm{C}$ and 3 in the context of the scR1 secondary structure. The arrowheads are as in $A$ and $B$.

The major difference between digestion patterns of SRP $\Delta 54$ and SRP $\Delta 54 \Delta 65$ was the presence of additional, small $\sim 30$-base fragments derived from SRP $\Delta 54 \Delta 65$ that hybridized to probe 297-279 (Fig. 3C). Thus, Sec65p protects, and most likely binds, nucleotides in this portion of the RNA.

\section{Primer extension analysis}

To map the $5^{\prime}$-ends of fragments generated from scR1 by micrococcal nuclease, we used primer extension (Fig. 4). Oligonucleotides binding the $3^{\prime}$-end or central portion of scR1 were used to prime reactions on RNA extracted from 30 -min digestions of SRP and SRP $\Delta 54$, within which all major degradation species were detected. Major stops were seen between C450 and A444 for both SRP and SRP $\Delta 54$ RNA in reactions carried out with 3 '-primer 522-498. The pattern of stops at the $5^{\prime}$-end was also similar for SRP and SRP $\Delta 54$ RNA samples, with several around A163 (data not shown) and A88.

The pattern of stops within the middle portion of scR1 differed between SRP and SRP $\Delta 54$ RNA. RNA extracted from digestions of SRP $\Delta 54$ revealed stops at A382, U369, and A365. These all map within the Srp54p-protected re- gion of scR1 defined by the hybridization data and discussed above. As these were the only significant stops, they represent strong cleavages that occurred before others. These were not observed in extensions on RNA from wildtype SRP digestions, which contained stops at C323 and A316 and several between U241 and A228 (Fig. 4). Other stops were also seen in these reactions, confirming the slow kinetics of cleavages generating the core fragment (data not shown). Comparison with the hybridization data indicated that the stops between U241 and A228 represent the $5^{\prime}$-end of the core fragment, whereas those at A316 and C323 are those that result in separation of the core into its two halves.

In sum, hybridization and primer extension data indicate that a central region of scR1, covering approximately $\mathrm{nt}$ 228-394 is resistant to micrococcal nuclease. This core fragment contains regions protected by both Srp54p and Sec65p consistent with it corresponding to the S-domain of scR1. In the absence of Srp54p, cleavage occurs in the Srp54pbinding region, followed by rapid degradation of the resulting fragments. Within the $5^{\prime}$ - and $3^{\prime}$-ends of scR1, several sites are cleaved by the nuclease to release stable fragments. The generation of these fragments is not altered in the absence of Srp54p or Sec65p. 



FIGURE 4. Primer extension. RNA extracted from a 30-min micrococcal nuclease digestion of wild-type SRP and SRP $\Delta 54$ (lanes 1,3), and undigested SRP (lane 2) were used in primer extensions with $\left[{ }^{32} \mathrm{P}\right]$-end-labeled primers and run next to sequencing reactions carried out with the same primers. Specific regions of autoradiograms are shown from reactions carried out with: (left panels) primer 315-296; (right panels) primers 394-375 (top) or 522-498 (middle and bottom). (Bottom right panel) The sequence T447GGC450 is compressed. The cartoon at the top summarizes $5^{\prime}$-ends of fragments detected in both wild type and SRP $\Delta 54$, in wild type only, or in SRP $\Delta 54$ only (gray, black, and white filled arrows, respectively).

\section{The S-domain}

A putative domain IV had previously been modeled from nt 324-370 of scR1 (Althoff et al. 1994), which are within the region of the RNA protected by Srp54p from micrococcal nuclease. In contrast to other candidates (data not shown), this model places conserved nucleotides in equivalent positions to other SRP RNAs (Fig. 5, cf. A, B, and C). We used and extended this model and built, $5^{\prime}$ to domain IV, a stem-loop (nt 249-296) closed by a GNAR tetraloop. This stem-loop contains nucleotides protected by Sec65p and constitutes a putative domain III. Domains III and IV are separated by a short stem-loop that contains the A316 cleavage site (Fig. 4). Sequences immediately $5^{\prime}$ to domain III and $3^{\prime}$ to domain IV form a helix interrupted by two bulges, akin to domain II of higher eukaryotic SRP RNA. A228, the $5^{\prime}$-end of the core scR1 fragment (Fig. 4), is within the $5^{\prime}$-side of one of these bulges. Once modeled, the $\mathrm{S}$-domain encompassed the whole core fragment released by micrococcal nuclease plus several additional $5^{\prime}$ and $3^{\prime}$ bases. To confirm this proposed S-domain and discriminate accurate secondary structures for the remaining portions of the RNA, we turned to further experimental approaches.

\section{Mutation of domains III and IV}

As SRP is stable in vivo in the absence of Srp54p or Srp54p and Sec65p, we reasoned that mutations in scR1 that prevented these proteins from binding should produce stable particles. The mutants generated (Fig. 6A; Table 1) tested the importance of the internal asymmetric and symmetric bulges of the proposed domain IV and the GNAR tetraloop of domain III.

A mutant lacking the internal loops of domain IV did not compensate for lack of genomic SCR1 ( $\triangle$ IVint; Fig. 6A,B).


FIGURE 5. $(A, B)$ The S-domains of scR 1 and human 7SL, and $(C)$ Ffh binding region of $E$. coli $4.5 S$ RNA. Domains II, III, and IV are indicated on scR1 as are helices 5-8 in 7SL as defined by Larsen and Zwieb (1991). (A) Black boxes indicate identity between SCR1 homologs in primary sequence placed equivalently in the secondary structure (see Figs. 8, 9); gray boxes are semiconserved (identical in all but one or two species or divided over two kinds of nucleotide), universally conserved motifs as in Figure 1A. $(B, C)$ Black-boxed bases are identical to $S$. cerevisiae. 


\section{A B C}
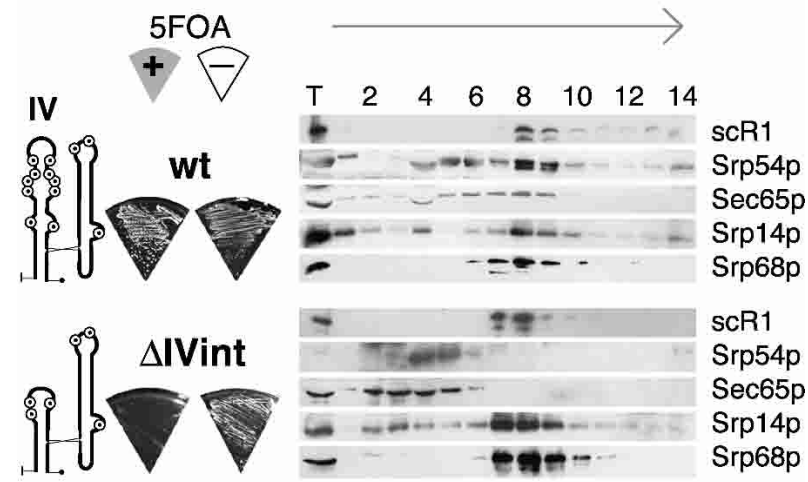

ScR1

Srp54p

Sec65p

Srp14p

Srp68p
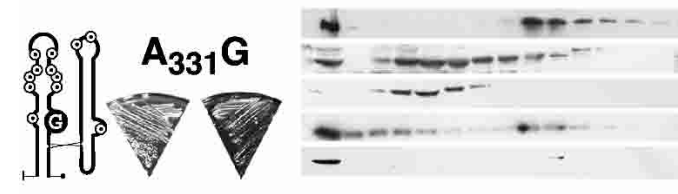

scR1

Srp54p

Sec65p

Srp14p

Srp68p
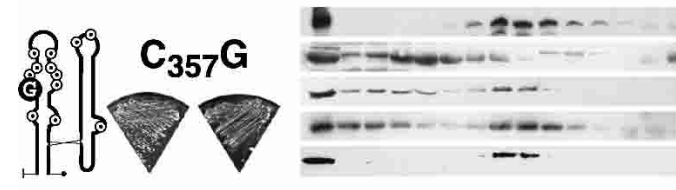

scR1

Srp54p

Sec65p

Srp14p

Srp68p
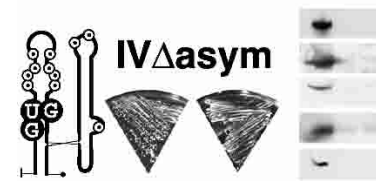

scR1

Srp54p

Sec65p

Srp14p

Srp68p

FIGURE 6. Mutations in domain IV affect SRP function and/or stability. Mutations $(A)$ described in the text and Table 1 are indicated in the cartoons with black circles containing the mutant nucleotide(s). Mutant alleles were tested for function by plasmid shuffle assay $(B)$. Sectors of 5-fluoroorotic acid (left), or control (right) plates are shown. Data are for mutants expressed from multicopy $(2 \mu)$ plasmids. Equivalent results were obtained for single-copy (CEN) plasmids. (C) Cell extracts were analyzed on $5 \%-20 \%$ sucrose gradients followed by Northern and Western blotting using a $\left[{ }^{32} \mathrm{P}\right]$-labeled probe for $\mathrm{scR} 1$ and antibodies against Srp54p, Sec65p, Srp14p, and Srp68p as indicated. The Srp54p panel of $\Delta$ IVInt is a longer exposure than all other Western blot panels as Srp54p was present at reduced levels in this mutant. The arrow indicates the direction of sedimentation.

Levels of Srp54p were reduced in cells expressing this mutant (data not shown), indicating that the protein was not assembled into $\Delta$ IVint SRP (Brown et al. 1994). Indeed, following sucrose gradient sedimentation, Srp54p and Sec65p were not associated with $\Delta$ IVint (Fig. 6C; note that the Srp54p panel is a significantly longer exposure than all other panels in this figure). However, other SRP proteins, including the S-domain component Srp68p and Alu-domain protein Srp14, were stably associated with $\Delta$ IVint, indicating that the overall structure of the RNA was unaffected by the deletion. Determinants for binding both Sec65p and Srp54p lie within domain IV (Batey et al. 2000; Hainzl et al. 2002; Kuglstatter et al. 2002; Oubridge et al. 2002), and the result is thus in agreement with our designation of this region of the RNA as domain IV.
Two single substitutions, C357G and A331G, tested the importance of conserved bases previously implicated in binding Srp54p homologs to their cognate RNAs (Batey et al. 2000; Kuglstatter et al. 2002). Surprisingly, cells expressing these mutant RNAs as the only scR1 grew as well as cells expressing wild-type scR1 (Fig. 6B). These scR1 mutants must therefore retain the correct fold, allowing all SRP proteins, including Srp54p, to bind to them. However, defects in stability of the SRP assembled on the mutant RNAs were detected on sucrose gradients (Fig. 6C). Following centrifugation, Srp54p was not significantly associated with particles assembled on either mutant scR1 and Sec65p was also

TABLE 1. Plasmids

\begin{tabular}{|c|c|c|}
\hline Plasmid & Vector $^{\mathrm{a}}$ & Insert \\
\hline \multicolumn{3}{|l|}{ Wild-type SCR1 } \\
\hline pRS316-SCR1 & pRS316 & SCR1 with flanking regions \\
\hline pScr1 & pRS4n2 & $\begin{array}{l}\text { 1.3-kb Acc65I-BamHI from } \\
\text { pRS316-SCR1 }\end{array}$ \\
\hline pCast & $\mathrm{pRS} 4 \mathrm{n} 2$ & $\begin{array}{l}\text { 1.6-kb Apal-Sacl PCR fragment } \\
\text { generated from S. castellii } \\
\text { genomic DNA }\end{array}$ \\
\hline pKluy & pRS4n2 & $\begin{array}{l}\text { 1.5-kb Apal-BamHI PCR fragment } \\
\text { generated from S. kluyveri } \\
\text { genomic DNA }\end{array}$ \\
\hline pZroux & pRS422 & $\begin{array}{l}\text { SCR } 1 \text { in pScr1 replaced by } 0.5-\mathrm{kb} \\
\text { blunted PCR-amplified Z. rouxii } \\
\text { SCR1 CDNA }\end{array}$ \\
\hline \multicolumn{3}{|l|}{ Mutants } \\
\hline plV $\Delta$ int & pRS4n2 & $\begin{array}{l}\text { PpuMl-BstEII of } S C R 1 \text { replaced } \\
\text { with oligonucleotides yielding } \\
\Delta \mathrm{C}_{330}-\mathrm{A}_{345}, \Delta \mathrm{T}_{352}-\mathrm{C}_{363}\end{array}$ \\
\hline $\mathrm{plV} \Delta$ & pRS4n2 & $\begin{array}{l}\text { PpuMl-BstEII of } S C R 1 \text { replaced } \\
\text { with oligonucleotides yielding } \\
\mathrm{A}_{331} \mathrm{G}, \Delta \mathrm{C}_{3}{ }^{32} \mathrm{~A}_{364}\end{array}$ \\
\hline $\mathrm{pC}_{357} \mathrm{G}$ & pRS4n2 & $\begin{array}{l}\text { PpuMl-BstEII of SCR1 replaced } \\
\text { with PCR product yielding } \\
\mathrm{C}_{357} \mathrm{G}\end{array}$ \\
\hline $\mathrm{pA}_{331} \mathrm{G}$ & $\mathrm{pRS} 4 \mathrm{n} 2$ & $\begin{array}{l}\text { Insertion of oligonucleotides into } \\
\text { BstB1-cut pIV } \Delta \text { yielding } \mathrm{A}_{331} \mathrm{G}\end{array}$ \\
\hline plV $\Delta$ asym & pRS4n2 & $\begin{array}{l}\text { Insertion of oligonucleotides into } \\
\text { BstB1-cut pIV } \Delta \text { yielding } \mathrm{A}_{331} \mathrm{G} \text {, } \\
\Delta \mathrm{C}_{332}, \Delta \mathrm{C}_{333}, \mathrm{~A}_{364} \mathrm{TG}\end{array}$ \\
\hline \multicolumn{3}{|l|}{ SRP isolation } \\
\hline pSRP14_21 & pRS424 & $\begin{array}{l}\text { SRP14 as Apal-Sall, SRP21 as } \\
\text { EcoRI-BamHI }\end{array}$ \\
\hline pSRP54_14_21 & pRS424 & $\begin{array}{l}\text { SRP54 as Bg/lI-Sacl PCR fragment } \\
\text { into pSRP14_21 }\end{array}$ \\
\hline pSRP68_72ZZ & pRS422 & $\begin{array}{l}\text { SRP68 as Aspl-Pm/l and } \\
\text { SRP72-ZZ as Xhol-Nael, Pm/l } \\
\text { and Nael blunt ended }\end{array}$ \\
\hline pSEC65_SCR1 & pRS426 & $\begin{array}{l}\text { SEC65 as HindIII-BamHI, SCR1 as } \\
\text { Bg/II-Sacl PCR fragment }\end{array}$ \\
\hline pSCR1 & pRS426 & $\begin{array}{l}\text { 1.1-kb HindIII-Nhel containing } \\
\text { SCR1 deleted from } \\
\text { pSEC65_SCR1 }\end{array}$ \\
\hline
\end{tabular}

*Constructs labeled pRS4n2 were made in both low-copy pRS412 (CEN, ADE2) and high-copy pRS422 $(2 \mu, A D E 2)$ vectors. 
dissociated from A331G SRP. In contrast, in gradients of cells expressing C357G a proportion of Sec65p consistently migrated with SRP. Therefore, although the mutations did not prevent SRP assembly and function in vivo, they reduced the strength of interaction of Sec65p and particularly Srp54p with scR1. The stringent $(0.5 \mathrm{M}$ salt) conditions of the sucrose gradient highlighted this difference between the mutant and wild-type particles. We concluded from these experiments that the mutations had affected the strength of both Srp54p-scR1 and Sec65p-scR1 interactions.

A final domain IV mutant tested (IV $\Delta$ asym) was designed to collapse the asymmetric loop to $2 \mathrm{bp}$. This was predicted to prevent generation of the "RNA platform" from unpaired bases in the long strand of the loop seen as a crucial part of the SRP54-RNA interface in the E. coli and mammalian domain IV-SRP54 complexes (Batey et al. 2000; Kuglstatter et al. 2002). Surprisingly, this mutant also supported wild-type growth (Fig. 6B). However, as seen with the single point mutants, Srp54p and Sec65p were less tightly associated with the IV $\Delta$ asym RNA (Fig. 6C).

The tetraloop of human domain III is crucial for SRP19 binding to the RNA, and a single A149U substitution prevents formation of a stable SRP19-RNA complex (Zwieb 1992; Hainzl et al. 2002; Oubridge et al. 2002). In agreement with this observation, scR1 mutants in which the GGAA tetraloop of the putative domain III was either altered (to CGCG) or deleted were nonfunctional in vivo. Neither Sec65p nor Srp54p bound these mutant RNAs, although, like the domain IV mutants, other SRP proteins were associated with them (data not shown). We did not expect Srp54p to bind domain III mutants as, if Sec65p is not associated with scR1, Srp54p does not bind (Brown et al. 1994). In sum, the mutagenesis data, although consistent with our assignment of domains III and IV, indicate that some conserved bases in domain IV are not crucial for SRP function in $S$. cerevisiae.

\section{Identification of scR1 homologs}

Initial attempts to expand the S-domain model (Fig. 5A) to the whole of scR1 failed to provide a single convincing structure. We therefore took a phylogenetic approach. Comparative sequence analysis is a powerful tool in building RNA secondary structures (Noller and Woese 1981; Chen et al. 2000; Harris et al. 2001; Gutell et al. 2002). Central to this are principals of covariation and maintenance of base-pairing in equivalent helical regions of homologous RNAs. Incorrectly assigned helices are revealed by failure to retain base-pairing between species. To enable comparative sequence analysis with scR1 we identified sequences homologous to SCR1 in the genomes of five yeast species related to $S$. cerevisiae. These were the sensu stricto species Saccharomyces bayanus, Saccharomyces mikatae, and Saccharomyces kudriavzevii, and more distantly related Sac- charomyces castellii and Saccharomyces kluyveri (Materials and Methods).

As the level of sequence identity to $S$. cerevisiae scR1 was relatively low for the sequences from $S$. castellii and $S$. kluyveri, these were experimentally confirmed as SRP RNAs. RNAs of the expected size were detected in these yeast species by hybridization to specific probes. The RNAs were also immunoprecipitated from native extracts by affinity-purified antibodies against $S$. cerevisiae Sec65p (data not shown). The S. castellii and S. kluyveri SCR1 homologs were therefore designated ScaSCR1 and SklSCR1, respectively.

To further verify their function as SRP RNAs, we tested whether ScascR1 and SklscR1 could compensate for lack of endogenous $S$. cerevisiae scR1. Strains containing these heterologous genes as the only source of SRP RNA were readily generated and grew as well as wild type at $25^{\circ} \mathrm{C}$ and $30^{\circ} \mathrm{C}$ (Fig. 7A; Materials and Methods). Thus, primary sequence and secondary structure necessary for binding $S$. cerevisiae SRP proteins are conserved to these scR1 homologs. Cells expressing either heterologous RNA were, however, slightly cold sensitive, and those containing ScascR1 also grew slower than cells expressing wild-type scR 1 at $37^{\circ} \mathrm{C}$. Therefore, these RNAs did not fully compensate for lack of scR1 under these more stringent conditions.

Last we mapped the $5^{\prime}$ - and $3^{\prime}$-ends of ScascR1 and
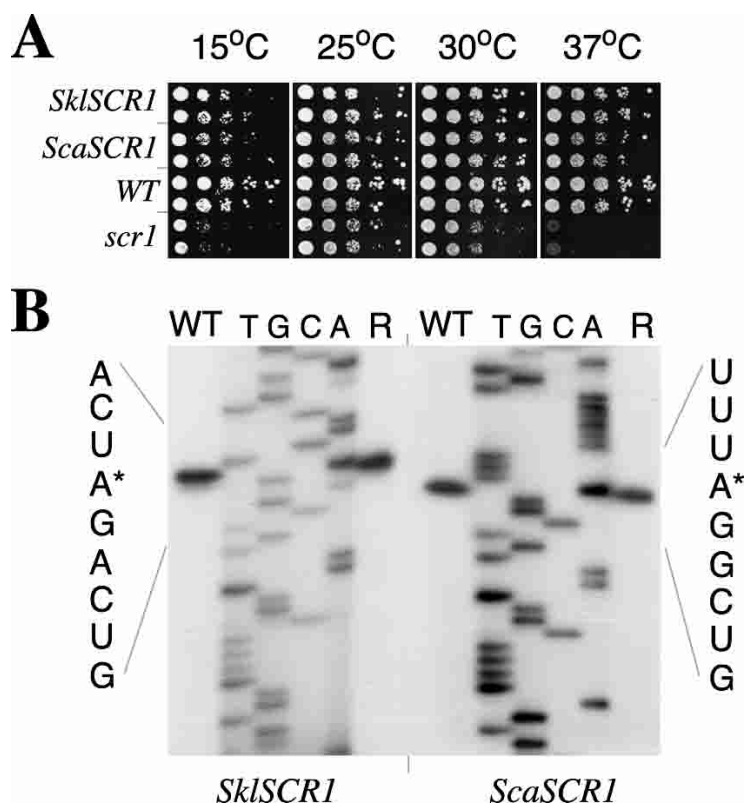

FIGURE 7. Characterization of SCR1 homologs. (A) S. cerevisiae carrying indicated SCR1 genes as the sole source of SRP RNA were spotted on plates in serial 10 -fold dilutions and incubated at the temperatures indicated. (WT) Wild type S. cerevisiae SCR1, scr1, a thermoand cold-sensitive mutant allele (R.W. van Nues and J.D. Brown, unpubl.). Data were obtained with RNAs expressed from low-copy (CEN) plasmids. (B) $5^{\prime}$ termini of S. kluyveri and S. castellii scR1 expressed either endogenously (WT) or in S. cerevisiae (R) were mapped by primer extension (Materials and Methods). The surrounding DNA sequence is given beside each panel and the mapped transcriptional start site indicated $\left.{ }^{*}\right)$. 
SklscR1 (Figs. 7B, 8; Materials and Methods). Regions encompassing SCR1 homologs were then aligned (Fig. 8). This revealed that the most conserved regions of the RNA were toward the $5^{\prime}$-end and within the core fragment modeled into the S-domain structure (Fig. 5).

\section{Complete secondary structures for scR1 and related SRP RNAs}

Phylogenetic comparison using the scR1 sequences, together with data from nuclease digestion, provided sufficient information for us to generate complete secondary structure models for Saccharomyces SRP RNAs (Fig. 9A-C).

\section{S-domain}

The S-domain for all the Saccharomyces SRP RNAs could be modeled similarly to the structure outlined above for scR1 (Fig. 5). The overall primary sequence and secondary structure were highly conserved. Within this domain, the major differences between the RNAs were in the "extra" stemloop separating domains III and IV, which is not seen in other SRP RNAs. Conserved nucleotides are found in the asymmetric and symmetric loops of domain IV of all species (A331, A340GG342, A355GC357, and A364; S. cerevisiae numbering). The terminal closing loop of domain IV, typically GNRA in bacterial and higher eukaryotic SRP RNAs, is replaced with GNUUYA in Saccharomyces sequences. In $S$. castellii and S. bayanus, extra base-pairing is possible within the domain IV symmetric loop, pre-empting the closing of the loop seen in crystal structures of S-domain complexes (Hainzl et al. 2002; Oubridge et al. 2002). Sequence conservation between Saccharomyces species extends up to the domain II helix formed from U215-U224 and G385-A395 and four following unpaired bases, G396-C399. Within the whole domain II-IV region, no base changes reduce helical propensity, although several bulged bases are present in only some species (e.g., C323, U379). Without this highly conserved portion, domain II could be extended in all six SRP RNAs with an irregular helical segment of 9-11 bp.

\section{The Alu-domain}

The 5'-terminus of each Saccharomyces SRP RNA can form a short stem-loop revealing a GUAAU loop overlapping the universally conserved motif UGUA. Equivalent loops have been proposed for other yeast SRP RNAs (Schizosaccharomyces pombe, Kluyveromyces lactis, and Yarrowia lipolytica), and this loop has been modeled previously for $S$. cerevisiae scR1 (Strub et al. 1999). Close proximity of $5^{\prime}$ - and $3^{\prime}$-ends



FIGURE 8. Alignment of SCR1 homologs. Where known, numbering starts at the first transcribed base as defined by $5^{\prime}$-end mapping (Fig. 7 ; Felici et al. 1989; data not shown). $3^{\prime}$-ends of S. castellii, S. kluyveri, and Z. rouxii are as determined (Materials and Methods). Saccharomyces sequences, apart from S. paradoxus (Kellis et al. 2003), were from species sequenced by Cliften et al. (2001). 
is a common feature of all SRP RNAs, and beyond the 5' stem-loop, an irregular helix can be formed between nt 20-35 and 501-516 (subdomain IA; Fig. 9). This helix varies in length in S. kluyveri and S. castellii, and is supported by nine base changes in sensu stricto Saccharomyces scR1 RNAs that strengthen or maintain base-pairing.

Remaining portions of scR1, between the subdomain IA helix and the S-domain (nt 36-198 and 417-500), adopt Saccharomyces-specific structures that we term subdomains IB-F. Of these subdomains, IB, a stem-loop formed from bases 43-77, contains the RNA polymerase III B-box motif (Dieci et al. 2002). Subdomain IB is supported by a nuclease cleavage site that, by Northern blotting, maps to its terminal loop and produces an $\sim 60$-nt fragment from the $5^{\prime}$-end of scR1 (Fig. 2C, panels 30-11 and 62-42). This stem-loop was previously noted in S. cerevisiae scR1 by Strub et al. (1999), whose model incorporates the 5' 99 nt of the RNA (Fig. 9A inset). The final portion of their proposed structure, a helix between bases 20-35 and 79-95, is, however, inconsistent with the $5^{\prime}$ and $3^{\prime}$ termini of scR1 forming the subdomain IA helix and, moreover, cannot be formed from the $S$. castellii or S. kluyveri RNAs. Instead we propose a helix formed by nucleotides on either side of IB (37-41 and 79-87) and nt 139-154, that are part of the next sequence block with a high level of identity between Saccharomyces species (121154; Fig. 8). This can be formed in all the scR1 homologs, and all base changes in sensu stricto homologs (except U84C in S. bayanus) retain base-pairing, supporting this further.

Extending out from this helix, nt 88-137 comprise a less conserved subdomain IC with three variable stem-loops. In ScascR1, subdomain IC has 18 more nucleotides than scR1, in $S k l s c R 1$ it has 10 less, and 11 positions differ between scR1 in the closely related species. The first stem-loop (nt 90-100) is absent in SklscR1, but is twice as long in ScascR1. Six compensatory base changes (of which two form a new base pair) between the sensu stricto species support the second stem-loop (nt 103-120), which is also extended in ScascR1. The third stem-loop contains the highest degree of primary sequence conservation but has a lower propensity to form secondary structure.

Nucleotides 455-500 toward the 3'-end of scR1 form subdomain ID. This comprises two stem-loops. The stem between nt $482-487$ and $493-498$ is supported by seven compensatory base changes in sensu stricto species and is extended in both ScascR1 and SklscR1. The second stemloop contains a variable closing loop of 6-14 nt that is susceptible to nuclease attack. Northern analysis revealed early (although incomplete) cleavage generating an $\sim 45$-nt fragment from the $3^{\prime}$ portion of scR1. This was detected with 3'-primer 522-497 (but not with 480-461; Fig. 2C), and the size of this fragment is consistent with cleavage in the subdomain ID 462-475 loop.

Numerous other possibilities were examined for the secondary structure of subdomains IC and ID. None was sup- ported by phylogenetic variation (data not shown), and in most cases they contained large single-stranded and/or irregular helical regions that would not correlate with the compact structure of these portions of scR1 indicated by the nuclease digestion.

Bordering onto subdomains IC and ID, a helical segment formed from nt 155-164 and 444-454 extends the rod-like core of scR1. Again, base changes between the closely related Saccharomyces species do not affect formation of this helix. A similar, less regular helix can also be formed in ScascR1, although it is absent in SklscR1. Remaining nucleotides (165-197 and 418-443) form two stem-loops (subdomains IE and IF, respectively). Subdomain IE is extended in ScascR1, but reduced to a 4-bp stem closed by a GNAR tetraloop in SklscR1. Subdomain IF is absent from both ScascR1 and SklscR1.

\section{A test of the model}

After completion of the secondary structures described above, we identified the Zygosaccharomyces rouxii and Saccharomyces paradoxus SRP RNAs (Materials and Methods; Fig. 9). These provided further tests of our model. S. paradoxus is a sensu stricto Saccharomyces species (Kellis et al. 2003) and, like the other species closely related to S. cerevisiae, its SRP RNA sequence contained few differences to scR1. With two exceptions (U146C and G221A; Fig. 9A), these fitted the base-pairing proposed in the model for scR1. Z. rouxii is slightly closer in evolutionary distance to S. cerevisiae than S. kluyveri (Souciet et al. 2000). Like $S k l s c R 1$ and ScascR1, the $Z$. rouxii RNA (ZroscR1) complemented lack of endogenous scR1 in S. cerevisiae (data not shown). We built ZroscR1 into a structure similar to the other scR1 homologs, retaining base-pairing and positioning of conserved regions (Fig. 9D). The main deviations were in the variable subdomains IC and ID of the Aludomain. The overall consistency between the secondary structures, particularly given the (substantial) deviations in primary sequence between $S$. cerevisiae, S. castellii, $S$. kluyveri, and $Z$. rouxii, argues strongly in their favor.

\section{DISCUSSION}

SRP is a conserved ribonucleoprotein. The secondary structures of scR1 and its close homologs reflect this, being similar to those in other eukaryotic SRP RNAs. Importantly, the data that we obtained from biochemical analysis and mutagenesis are consistent with the model generated from phylogenetic comparison. Mutations within regions of scR1 defined as Srp54p and Sec65p binding sites by nuclease digestion affect association of these proteins with the RNA. Within the completed model, built largely on the basis of conservation of base-pairing, nearly all mapped micrococcal nuclease cleavage sites lie within unpaired segments (loops) and/or at junctions between helices, consistent with the ac- 


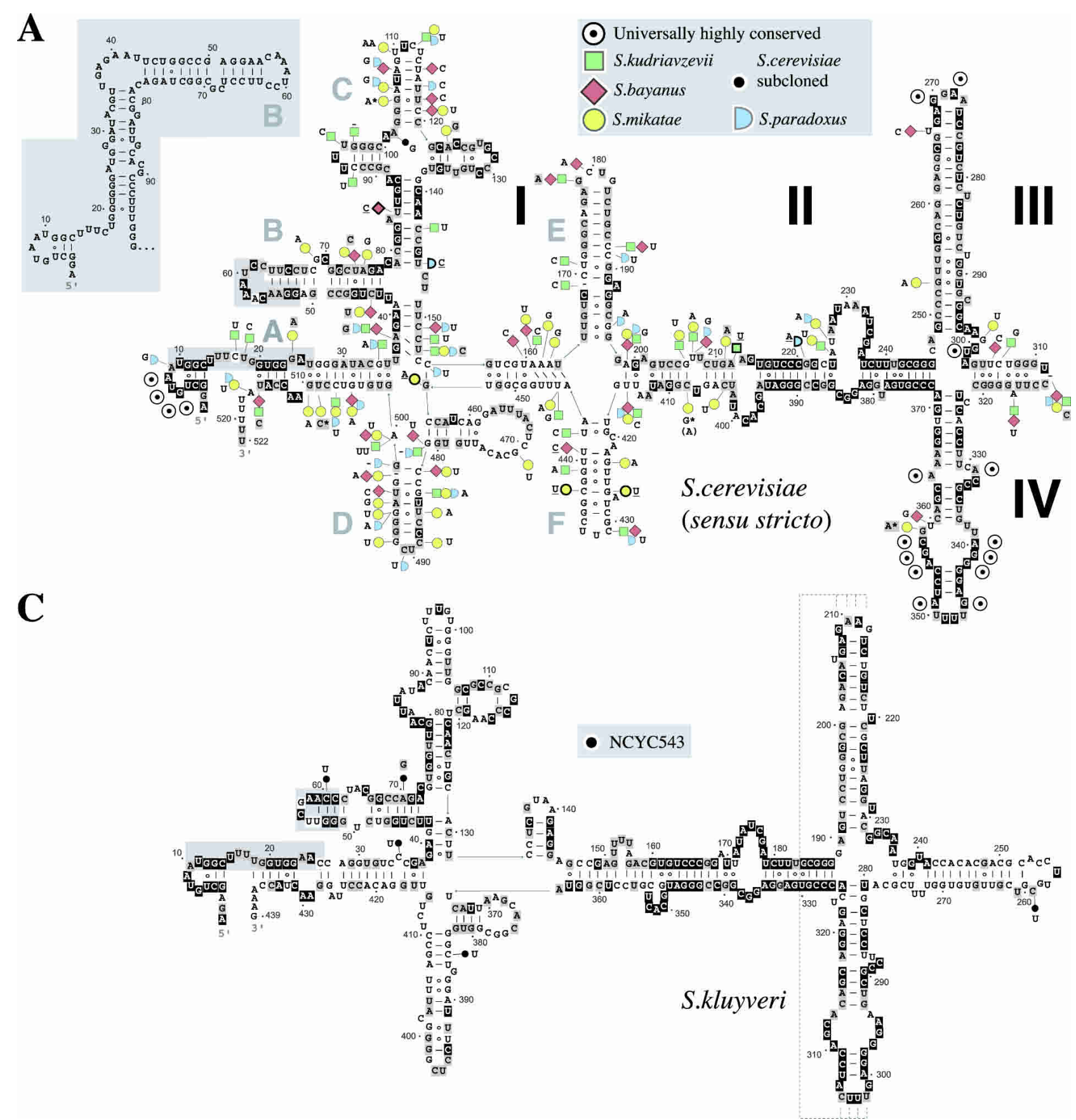

FIGURE 9. (Continued on next page)

tivity of the nuclease (Rushinsky et al. 1962). For example, the bulge in domain II (bases 224-235) comprises a major cleavage site in intact SRP, as do junction positions within the cloverleaf of subdomain IC (A88 and A101). The availability of both close homologs with few base changes to $S$. cerevisiae scR1 and more distant sequences was important. We were able to use primary sequence conservation and maintenance of base-pairing in more conserved regions of the RNA and overall maintenance of structure in more divergent regions. The demonstration that ScascR1, $S k l s c R 1$, and ZroscR1 functioned in S. cerevisiae was important as this indicated that all crucial sequences and structures within scR1 are conserved to these homologs.

The large size of scR1 compared with other eukaryotic SRP RNAs indicated extra domains or expansions. This is, indeed, the case, and the major differences between scR1 and other eukaryotic SRP RNAs are in the Alu-domain (subdomains IB-F). The cloverleaf IC, with a relatively con- 


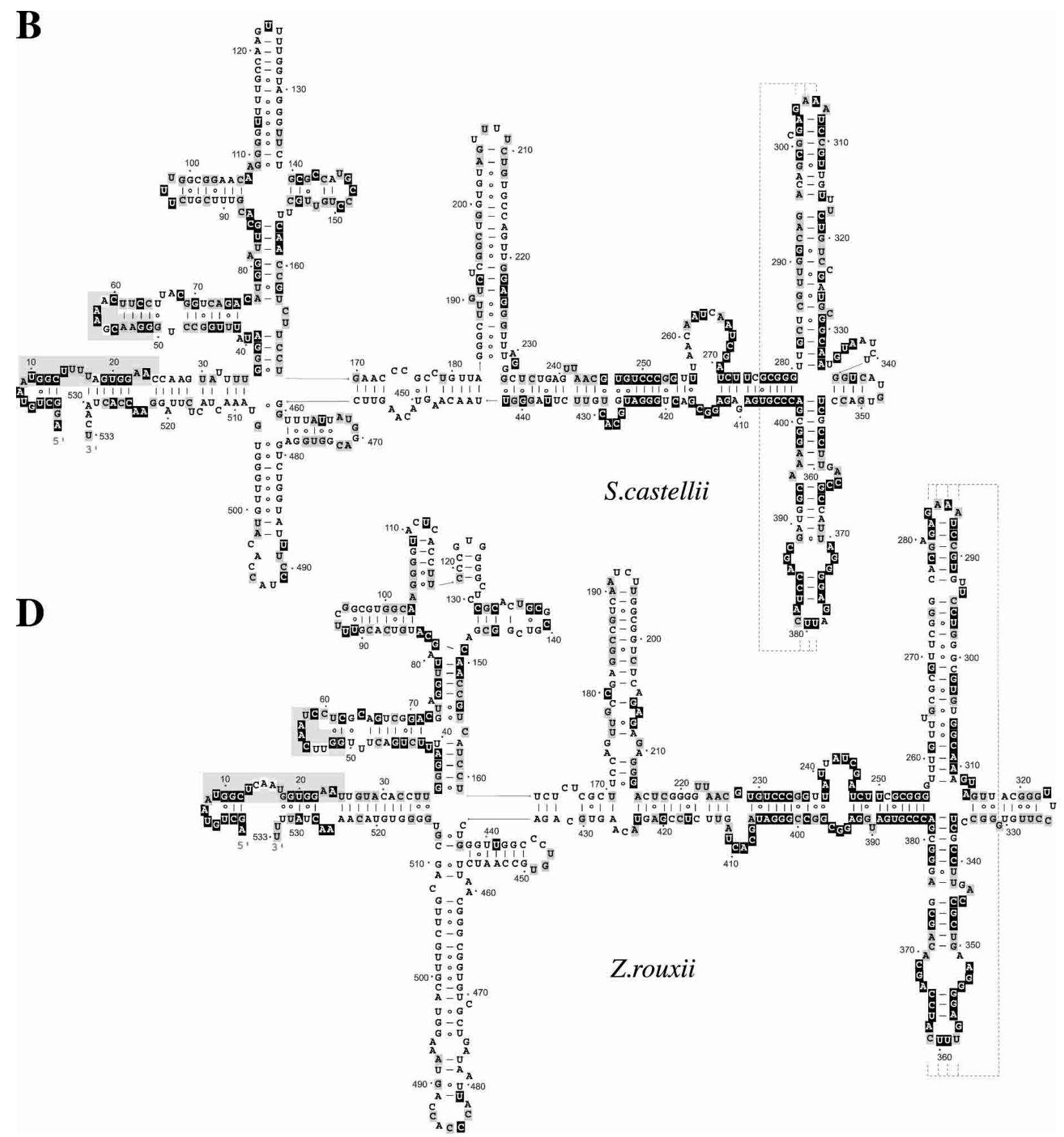

FIGURE 9. Secondary structures (A) S. cerevisiae scR1 (and other sensu stricto species) with the structure proposed by Strub et al. (1999) for bases 1-99 inset at the left. The box at the top provides a key to the bases that differ from the $S$. cerevisiae sequence. The symbols of those bases that weaken local secondary structure are outlined in black, and the letter underlined. S. mikatae nucleotides indicated by ${ }^{*}$ are as in Cliften et al. (2001), or differ ( ) according to Kellis et al. (2003). (B) S. castellii, (C) S. kluyveri, and (D) Z. rouxii SRP RNAs. See text for details. Shading and conserved motifs are as in Figures 2 and 5 for Saccharomyces RNAs. RNA polymerase III A- and B-boxes (Dieci et al. 2002) are in gray.

served core formed by long-distance interactions and greater variation at regions further from the core, is indicative of an expansion segment as found in ribosomal RNA (Gerbi 1996). This region of scR1 is also reminiscent, both in structure and placement, of the tRNA-like molecule identified as a second RNA component of Trypanosomatid SRP (Beja et al. 1993; Liu et al. 2003). It remains to be seen whether the IC region is important or dispensable for scR1 function.

In addition to primary sequence and secondary structural conservation of stem-loop IB, additional evidence for this comes from ribonuclease V1 digestion (Strub et al. 1999), which revealed that most bases in the stem are paired. The high level of sequence conservation of this region of scR1 
indicates that it has an important role. Conservation may be a corollary of the essential RNA polymerase III B-box within the DNA encoding this region (Dieci et al. 2002). However, IB may also, for example, provide the binding site for Srp21p, which we identified in available sequence data for all Saccharomyces species (R.W. van Nues and J.D. Brown, unpubl.). Our structure emphasizes the fact that, although it contains conserved elements, the Alu-domain of SRP RNA is extremely variable. This is also reflected at the protein level, the $S$. cerevisiae Alu-domain containing the Srp14p homodimer and Srp21p, higher eukaryotes SRP9/ 14, archaebacteria no proteins (Zwieb and Eichler 2001), and Bacillus subtilis the HBsu protein (Nakamura et al. 1999). It is not known at present whether elongation arrest is retained in bacterial and archaebacterial SRPs that contain an Alu-domain.

Bases important for protein binding within domains III and IV of other SRP RNAs are conserved in scR1. Indeed, the major difference is the domain IV terminal loop, GNUUYA in species examined here, which provides an exception to the typical GNRA loop (Rosenblad et al. 2003). Similar GYUUCA loops are, however, found in plant SRP RNAs and the recently identified Neurospora crassa SRP RNA reveals a GUUCCA loop (Regalia et al. 2002). Crystallographically, interactions have been defined between bases of the domain IV and III terminal loops (Hainzl et al. 2002; Oubridge et al. 2002) and the two "solutions" to the domain IV loop may permit interactions with the invariant GNAR loop of domain III necessary for complete SRP assembly.

In structures of both archaebacterial and human S-domain complexes domain III is in rigid conformation with continuous, predominantly Watson-Crick and G-U, base pairs throughout the helix (Hainzl et al. 2002; Oubridge et al. 2002). In the Saccharomyces secondary structures, domain III contains several bulged bases, particularly conserved in position toward its tip. These are likely to alter the rigidity or conformation of the helix in complex with Sec65p, providing a different geometry to the S-domain. This could, for example, enable specific tertiary interaction of domains III and IV terminal loops. Interestingly, the possibility of base-pairing between these loops is maintained in all the yeast species described here (Figs. 5A, 9). Overall, our results indicate a variation on the $\mathrm{S}$-domain conformation (Hainzl et al. 2002; Kuglstatter et al. 2002; Oubridge et al. 2002) accentuated by the presence of an extra, yeast-specific helix that may stack on domain III (Fig. $5 \mathrm{~A})$.

Amino acids within Sec65p and Srp54p that contact RNA are predominantly conserved in S. cerevisiae, indicating that the RNA-protein interfaces are likely similar to those in other organisms (data not shown). The mild phenotypes of mutations designed to disrupt the scR1-Srp54p interface in domain IV were surprising. A C62G mutation in 4.5S RNA, equivalent to $\mathrm{C} 356 \mathrm{G}$ examined here, is lethal in E. coli and prevents Ffh association with the RNA in vitro (Wood et al. 1992). However, several other 4.5S mutations still allow growth while reducing the strength of the Ffh-4.5S interaction (Wood et al. 1992). Similarly, several mutations within domain IV of Schizosaccharomyces pombe SRP RNA have little or no phenotype in vivo, yet decrease stability of the particle (Liao et al. 1992; Selinger et al. 1993). The situation is presumably similar in S. cerevisiae, and multiple interactions between RNA and protein components must allow assembly and function in the absence of part of the interaction surface.

In contrast to the single point mutations, IV $\Delta$ asym was designed to prevent formation of the RNA platform, formed by the bases in the long strand of the asymmetric loop of domain IV. This is a major part of the RNA-Srp54p interaction and is contacted by two conserved arginines (402 and 405 in human SRP54; Kuglstatter et al. 2002). The RNA platform also hydrogen-bonds to the symmetric loop, contributing to the overall conformation of domain IV (Batey et al. 2000; Kuglstatter et al. 2002). There are many variations to the asymmetric loop even within the sequences analyzed here. In S. kluyveri, the counterpart of A364 on the short side of the asymmetric loop can be pulled into the helix by either of two Us in the long strand replacing A331. $Z$. rouxii lacks a counterpart to $\mathrm{A} 364$ and has no unpaired bases on the short strand of the loop. Despite these and other variations (Rosenblad et al. 2003), the asymmetric nature of the loop with three or more unpaired bases in its long strand is maintained throughout evolution. The viability of S. cerevisiae expressing IV $\Delta$ asym is then all the more surprising and emphasizes significant flexibility in the scR1Srp54p interaction.

The scR1-Sec65p interaction is weakened by the domain IV mutations. It is unlikely that reduced Srp54p affinity for these mutant RNAs destabilizes the Sec65p-scR1 interaction as this protein remains stably SRP-associated in the absence of Srp54p (Brown et al. 1994). The main binding site of Sec65p can be expected to be at the loops of both domains III and IV (Hainzl et al. 2002; Oubridge et al. 2002), and the decreased affinity of Sec65p for scR1 domain IV point mutants thus indicates that complete integrity of domain IV is required for full Sec65p interaction. The conformation of the domain may be altered by the mutations, or there may conceivably be yeast-specific contacts between Sec65p and the central portion of domain IV.

As in mammalian SRP (Gundelfinger et al. 1983; Siegel and Walter 1986), the Alu- and S-domains of S. cerevisiae SRP are readily separated by nuclease. Regions of scR1 that lie at the junction between these domains are the least conserved. They may, therefore, provide a "linker" separating the important functions of signal sequence binding and elongation arrest. Eukaryotic SRP is proposed to span the ribosome from the nascent chain exit pore, where it binds nascent signal sequences (Pool et al. 2002), to the elongation factor binding site, where it may mediate elongation 
arrest (Andrews et al. 1987; Siegel and Walter 1988). As ribosomal size differs little in eukaryotes, it is not surprising that the overall "length" of yeast SRP is similar to that of the mammalian particle: 95 bases from the conserved Aludomain loop to the terminal loop of domain IV in both scR1 and human 7SL RNA.

The structure that we have provided here may be refined by further and ongoing experiments. Chemical modification of scR1 in intact SRP and SRP $\Delta 54$ has already revealed differences in accessibility of nucleotides in domain IV in these particles, further confirming the assignment of this region of the RNA (J.D. Brown, unpubl.). At the outset, we aimed to place scR1 within the context of existing structures of SRP RNA, and we have achieved this. Three-dimensional structures of the ribosome, translocon, and SRP receptor are available. This information, together with structural information on portions of SRP RNA from other organisms, can be combined with the secondary structure of scR1 to enable interpretation of genetic and biochemical data. Insight into the roles of the SRP RNA in the functions of SRP, and interactions it has with the ribosome, the SRP receptor, and, perhaps, components of the translocation machinery should also be forthcoming. Finally, the availability of purified, overexpressed yeast SRP will facilitate direct structural studies of this particle.

\section{MATERIALS AND METHODS}

\section{Reagents, yeast strains, and analysis}

Affinity-purified rabbit anti-Srp14p and anti-Srp68p (Brown et al. 1994), anti-Srp54p (Hann and Walter 1991), and sheep antiSec65p (raised at Diagnostics Scotland, Carluke, UK) bound to proteins on Western blots were visualized using HRP-coupled secondary antibodies and chemiluminescence. Plasmids are described in Table 1. Mutations and clones generated from PCR-amplified fragments were verified by sequencing. Genes encoding each individual SRP component cloned into multicopy plasmids and subsequently used to overexpress SRP were also tested to ensure that they complemented growth defects of strains deleted for the chromosomal copy of the gene. S. cerevisiae strains were BHY116 (srp54::LYS2; Hann and Walter 1991), CSY186 (sec65::HIS3; Stirling and Hewitt 1992), TR1 (trp1, his3, ura3, ade2, lys2, MATa/ $\alpha$; Parker et al. 1988), and JDY483 (scR1::TRP1, trp1-1, ura3-1, ade2-1, his3-11,-15, leu2-3,-112, can1-100, MATa, pRS316-SCR1). Heterologous and mutant SCR1 were tested in a plasmid shuffle assay in strain JDY483. Transformants were streaked onto 5-fluoroorotic acid (Melford Laboratories) plates (Guthrie and Fink 1991) to counterselect against pRS316-SCR1. Colonies containing complementing plasmids were then grown at $15^{\circ} \mathrm{C}, 24^{\circ} \mathrm{C}, 30^{\circ} \mathrm{C}$, and $37^{\circ} \mathrm{C}$ to test for conditional phenotypes. Colonies containing noncomplementing scrl plasmids were rescued from 5-fluoroorotic acid after $1 \mathrm{wk}$, cells lacking SRP function growing extremely slowly. Cell extracts were made, fractionated on sucrose gradients, and analyzed as described (Hann and Walter 1991; Mason et al. 2000). S. castellii CBS4309, S. kluyveri NCYC543, and $Z$. rouxii NCYC568 (CBS732) were obtained from the National Collection of Yeast Cultures.

\section{Isolation and enzymatic digestion of SRP}

SRP, SRP $\Delta 54$, and SRP $\Delta 54 \Delta 65$ were purified from strains TR1 (pSRP54_14_21, pSRP68_72ZZ, and pSEC65_SCR1; wild type), BHY116 (pSRP14_21, pSRP68_72ZZ, and pSEC65_SCR1; SRP 54 ), and CSY186 (pSRP14_21, pSRP68_72ZZ and pSCR1; SRP $\Delta 54 \Delta 65$ ). Purification was as described (Mason et al. 2000) except that EGTA was omitted from the final steps to prevent inhibition of S7 micrococcal nuclease (Roche) used for digestion. Srp54p often resolved into two species in the purified SRP. Nterminal sequencing indicated that it was intact in both Srp54p species, and the protein is therefore susceptible to proteolysis toward its $\mathrm{C}$ terminus. Next, $10 \mu \mathrm{L}$ samples of SRP $(\sim 5 \mu \mathrm{g})$ in buffer A (20 mM HEPES-KOH at pH 7.4, $150 \mathrm{mM}$ KOAc, $1 \mathrm{mM}$ EDTA, $2 \mathrm{mM}$ MgOAc, $2 \mathrm{mM}$ DTT, $0.02 \%$ [v/v] Nikkol) containing $14 \%$ $(\mathrm{v} / \mathrm{v})$ glycerol were combined with $10 \mu \mathrm{L}$ of $3 \times$ buffer A containing $3 \mathrm{mM}$ PMSF and 100 units S7 in $10 \mu \mathrm{L}$ of $\mathrm{H}_{2} \mathrm{O}$. Reactions at $37^{\circ} \mathrm{C}$ were started by adding $10 \mu \mathrm{L}$ of $4 \mathrm{mM} \mathrm{CaCl}_{2}$ and stopped by addition of $4 \mu \mathrm{L}$ of $50 \mathrm{mM}$ EGTA followed by phenol-chloroform extraction. RNA was resolved on $6 \%$ acrylamide $8 \mathrm{M}$ urea gels and blotted to Hybond-N (Amersham-Pharmacia) or used in primer extension reactions using M-MLV reverse transcriptase (Promega) according to the manufacturer's instructions.

\section{Isolation of heterologous SCR1 genes}

Genes encoding scR1 homologs of S. castellii, and S. kluyveri were amplified with Expand polymerase (Roche) from genomic DNA using oligonucleotides scast5' (aagggCCCTGACTCCATCGGAAC), scast3' (TATCATCACGAGCTCCAAATG), skluy5' (GCGGGcCC TCACGAAATACAGATAG), and skluy3' (ACACGgATCCACGA ACCATGAAAA) (lowercase letters indicate bases added to or changed from the genomic sequence to provide restriction sites). $Z$. rouxii SCR1 was isolated as described below for $3^{\prime}$-end mapping and cloned in between S. cerevisiae SCR1 5' - and 3'-flanking regions.

\section{5 '-end and 3 '-end mapping}

$5^{\prime}$-ends of SRP RNAs from S. castellii, S. kluyveri, and Z. rouzii were mapped by extension of $\left[{ }^{32} \mathrm{P}\right]-5^{\prime}$-end-labeled primers scast 87-68, skluy 87-67, and zroux 88-69, respectively, using M-MLV reverse transcriptase (Promega). Sequence reactions (Sequenase 2.0, USB) primed with the same labeled oligonucleotides were run alongside reverse transcriptions. Mapping of $3^{\prime}$-ends was achieved as described (Sinha et al. 1999) by ligating the $3^{\prime}$ cordycepin modified oligonucleotide tag-rev (GAACATTTTTTGGTTTAAACTA ATTAACCGTCCC-3'dA) to total RNA overnight at $4^{\circ} \mathrm{C}$ with $\mathrm{T} 4$ RNA ligase (NEB). This provided the binding site for tag-rev (TTCCCGGGACGGTTAATTAGTTTAAACC), which primed reverse transcription with Superscript II (Invitrogen). PCR was carried out on these templates using the appropriate $5^{\prime}$-primer (zroux 1-18, scast 268-286, or skluy 239-258), the $3^{\prime}$-primer tag-rev, and Expand high-fidelity polymerase (Roche). PCR products were sequenced directly.

\section{Phylogenetic sequence comparison}

The sequence of SCR1 used here is taken from the Saccharomyces Genome Database (http://www.yeastgenome.org/) and agrees with 
Felici et al. (1989) as updated by Dieci et al. (2002). The clone that we used for overexpression contains a single A102G change from this sequence. Saccharomyces sequence databases (http://genome. wustl.edu/projects/yeast/; Cliften et al. 2001, 2003) and (http:// www-genome.wi.mit.edu/annotation/fungi/comp_/yeasts/; Kellis et al. 2003) were searched using the provided GCG BLASTN facility. Then $0.6-\mathrm{kb}$ fragments containing putative SCR1 homologs were aligned using CLUSTALW (http://www.ebi.ac.uk/clustalw/) or Map (http://searchlauncher.bcm.tmc.edu/multi-align/multi-align. html). Alignment was manually improved with SeqUp (http:// iubio.bio.indiana.edu/soft/molbio/seqpup/java/), and conservation was highlighted using Boxshade 3.21 (http://www.ch.embnet. org/software/BOX_form.html). By searching the Génolevures database (http://cbi.labri.fr/Genolevures/; Souciet et al. 2000) for homologs of YER137C, the ORF directly upstream of SCR1 in S. cerevisiae, a fragment of $Z$. rouxii SCR1 (accession no. BN000170) was found. Full-length $Z$. rouxii SRP RNA sequence was then obtained as described above. SCR1 homologs (S. bayanus accession no. AJ550801; S. castellii, AJ550804; S. kluyveri, AJ550805; S. kudriavzevii, AJ550803; S. mikatae, AJ550802; Z. rouxii, AJ564197) have been deposited at EMBL. SCR1 homologs (S. bayanus, S. mikatae, S. paradoxus) were also annotated in published genomes (Souciet et al. 2000; Kellis et al. 2003). Secondary-structure modeling was guided by conserved SRP RNA characteristics (Introduction; Regalia et al. 2002; Rosenblad et al. 2003). An additional constraint was that the structures were expected to share a common core structure and be most deviant in regions absent from SRP RNAs of evolutionarily more distant species.

\section{ACKNOWLEDGMENTS}

We thank Mark Johnston for use of sequences ahead of formal publication of the Saccharomyces species' genome sequences. We are also grateful to the following: Joe Gray and Bob Liddell at the University of Newcastle Molecular Biology Unit for DNA and protein sequencing; Kate Brown and Leigh Venus for excellent technical assistance; Zofia Chrzanowska-Lightowlers, Kiyoshi Nagai, and Janet Quinn for constructive comments on the manuscript; and Christopher Blackwell for discussions during the course of the work. This work was funded by an MRC Senior NonClinical Research Fellowship to J.D.B.

The publication costs of this article were defrayed in part by payment of page charges. This article must therefore be hereby marked "advertisement" in accordance with 18 USC section 1734 solely to indicate this fact.

Received July 24, 2003; accepted September 22, 2003.

\section{REFERENCES}

Althoff, S., Selinger, D., and Wise, J.A. 1994. Molecular evolution of SRP cycle components: Functional implications. Nucleic Acids Res. 22: 1933-1947.

Andrews, D.W., Walter, P., and Ottensmeyer, F.P. 1987. Evidence for an extended 7SL RNA structure in the signal recognition particle. EMBO J. 6: 3471-3477.

Ares Jr., M. 1986. U2 RNA from yeast is unexpectedly large and contains homology to vertebrate $\mathrm{U} 4, \mathrm{U} 5$, and U6 small nuclear RNAs. Cell 47: 49-59.

Batey, R.T., Rambo, R.P., Lucast, L., Rha, B., and Doudna, J.A. 2000.
Crystal structure of the ribonucleoprotein core of the signal recognition particle. Science 287: 1232-1239.

Beja, O., Ullu, E., and Michaeli, S. 1993. Identification of a tRNA-like molecule that copurifies with the 7SL RNA of Trypanosoma brucei. Mol. Biochem. Parasitol. 57: 223-229.

Brown, J.D., Hann, B.C., Medzihradszky, K.F., Niwa, M., Burlingame, A.L., and Walter, P. 1994. Subunits of the Saccharomyces cerevisiae signal recognition particle required for its functional expression. EMBO J. 13: 4390-4400.

Bui, N. and Strub, K. 1999. New insights into signal recognition and elongation arrest activities of the signal recognition particle. Biol. Chem. 380: 135-145.

Chen, J.L., Blasco, M.A., and Greider, C.W. 2000. Secondary structure of vertebrate telomerase RNA. Cell 100: 503-514.

Cliften, P.F., Hillier, L.W., Fulton, L., Graves, T., Miner, T., Gish, W.R., Waterston, R.H., and Johnston, M. 2001. Surveying Saccharomyces genomes to identify functional elements by comparative DNA sequence analysis. Genome Res. 11: 1175-1186.

Cliften, P., Sudarsanam, P., Desikan, A., Fulton, L., Fulton, B., Majors, J., Waterston, R., Cohen, B.A., and Johnston, M. 2003. Finding functional features in Saccharomyces genomes by phylogenetic footprinting. Science 301: 71-76.

Dieci, G., Giuliodori, S., Catellani, M., Percudani, R., and Ottonello, S. 2002. Intragenic promoter adaptation and facilitated RNA polymerase III recycling in the transcription of SCR1, the 7SL RNA gene of Saccharomyces cerevisiae. J. Biol. Chem. 277: 6903-6914.

Felici, F., Cesareni, G., and Hughes, J.M.X. 1989. The most abundant small cytoplasmic RNA of Saccharomyces cerevisiae has an important function required for normal cell growth. Mol. Cell. Biol. 9: $3260-3268$.

Gerbi, S.A. 1996. Expansion segments: Regions of variable size that interrupt the universal core secondary structure of ribosome RNA. In Ribosomal RNA: Structure, evolution, processing and function in protein biosynthesis (eds. R. Zimmermann and A.E. Dahlberg), pp. 71-87. CRC Press, Boca Raton, FL.

Gundelfinger, E.D., Krause, E., Melli, M., and Dobberstein, B. 1983. The organization of the 7SL RNA in the signal recognition particle. Nucleic Acids Res. 11: 7363-7374.

Gutell, R.R., Lee, J.C., and Cannone, J.J. 2002. The accuracy of ribosomal RNA comparative structure models. Curr. Opin. Struct. Biol. 12: 301-310.

Guthrie, C. and Fink, G.R. 1991. Guide to yeast genetics and molecular biology. Academic Press, San Diego, CA.

Hainzl, T., Huang, S., and Sauer-Eriksson, A.E. 2002. Structure of the SRP19 RNA complex and implications for signal recognition particle assembly. Nature 417: 767-771.

Hann, B.C. and Walter, P. 1991. The signal recognition particle in $S$. cerevisiae. Cell 67: 131-144.

Harris, J.K., Haas, E.S., Williams, D., Frank, D.N., and Brown, J.W. 2001. New insight into RNase P RNA structure from comparative analysis of the archaeal RNA. RNA 7: 220-232.

Hughes, J.M., Konings, D.A., and Cesareni, G. 1987. The yeast homologue of U3 snRNA. EMBO J. 6: 2145-2155.

Jagath, J.R., Matassova, N.B., de Leeuw, E., Warnecke, J.M., Lentzen, G., Rodnina, M.V., Luirink, J., and Wintermeyer, W. 2001. Important role of the tetraloop region of $4.5 \mathrm{~S}$ RNA in SRP binding to its receptor FtsY. RNA 7: 293-301.

Keenan, R.J., Freymann, D.M., Stroud, R.M., and Walter, P. 2001. The signal recognition particle. Annu. Rev. Biochem. 70: 755-775.

Kellis, M., Patterson, N., Endrizzi, M., Birren, B., and Lander, E.S. 2003. Sequencing and comparison of yeast species to identify genes and regulatory elements. Nature 423: 241-254.

Kuglstatter, A., Oubridge, C., and Nagai, K. 2002. Induced structural changes of 7SL RNA during the assembly of human signal recognition particle. Nat. Struct. Biol. 9: 740-744.

Larsen, N. and Zwieb, C. 1991. SRP-RNA sequence alignment and secondary structure. Nucleic Acids Res. 19: 209-215.

Liao, X., Selinger, D., Althoff, S., Chiang, A., Hamilton, D., Ma, M., and Wise, J.A. 1992. Random mutagenesis of Schizosaccharomyces 
pombe SRP RNA: Lethal and conditional lesions cluster in presumptive protein binding sites. Nucleic Acids Res. 20: 1607-1615.

Liu, L., Ben-Shlomo, H., Xu, Y.X., Stern, M.Z., Goncharov, I., Zhang, Y., and Michaeli, S. 2003. The trypanosomatid signal recognition particle consists of two RNA molecules: A 7SL RNA homolog and a novel tRNA-like molecule. J. Biol. Chem. 278: 18271-18280.

Mason, N., Ciufo, L.F., and Brown, J.D. 2000. Elongation arrest is a physiologically important function of signal recognition particle. EMBO J. 19: 4164-4174.

Nakamura, K., Yahagi, S., Yamazaki, T., and Yamane, K. 1999. Bacillus subtilis histone-like protein, HBsu, is an integral component of a SRP-like particle that can bind the Alu domain of small cytoplasmic RNA. J. Biol. Chem. 274: 13569-13576.

Noller, H.F. and Woese, C.R. 1981. Secondary structure of 16 S ribosomal RNA. Science 212: 403-411.

Oubridge, C., Kuglstatter, A., Jovine, L., and Nagai, K. 2002. Crystal structure of SRP19 in complex with the S domain of SRP RNA and its implication for the assembly of the signal recognition particle. Mol. Cell 9: 1251-1261.

Parker, R., Simmons, T., Shuster, E.O., Siliciano, P.G., and Guthrie, C. 1988. Genetic analysis of small nuclear RNAs in Saccharomyces cerevisiae: Viable sextuple mutant. Mol. Cell. Biol. 8: 3150-3159.

Peluso, P., Herschlag, D., Nock, S., Freymann, D.M., Johnson, A.E., and Walter, P. 2000. Role of 4.5S RNA in assembly of the bacterial signal recognition particle with its receptor. Science 288: 16401643.

Pool, M.R., Stumm, J., Fulga, T.A., Sinning, I., and Dobberstein, B. 2002. Distinct modes of signal recognition particle interaction with the ribosome. Science 297: 1345-1348.

Regalia, M., Rosenblad, M.A., and Samuelsson, T. 2002. Prediction of signal recognition particle RNA genes. Nucleic Acids Res. 30: 33683377.

Rosenblad, M.A., Gorodkin, J., Knudsen, B., Zwieb, C., and Samuelsson, T. 2003. SRPDB: Signal recognition particle database. Nucleic Acids Res. 31: 363-364.

Rushinsky, G., Knight, C., Roberts, W., and Dekker, C. 1962. Studies on the mechanism of action of micrococcal nuclease II. Degradation of ribonucleic acid from tobacco mosaic virus. Biochim. Biophys. Acta 55: 674-682.

Selinger, D., Brennwald, P., Liao, X., and Wise, J.A. 1993. Identification of RNA sequences and structural elements required for assembly of fission yeast SRP54 protein with signal recognition particle RNA. Mol. Cell. Biol. 13: 1353-1362.
Siegel, V. and Walter, P. 1986. Removal of the Alu structural domain from signal recognition particle leaves its protein translocation activity intact. Nature 320: $81-84$.

. 1988. Binding sites of the $19-\mathrm{kDa}$ and $68 / 72-\mathrm{kDa}$ signal recognition particle (SRP) proteins on SRP RNA as determined by protein-RNA "footprinting." Proc. Natl. Acad. Sci. 85: 1801-1805.

Siliciano, P.G., Jones, M.H., and Guthrie, C. 1987. Saccharomyces cerevisiae has a U1-like small nuclear RNA with unexpected properties. Science 237: 1484-1487.

Sinha, K., Perumal, K., Chen, Y., and Reddy, R. 1999. Post-transcriptional adenylation of signal recognition particle RNA is carried out by an enzyme different from mRNA Poly(A) polymerase. J. Biol. Chem. 274: 30826-30831.

Souciet, J., Aigle, M., Artiguenave, F., Blandin, G., Bolotin-Fukuhara, M., Bon, E., Brottier, P., Casaregola, S., de Montigny, J., Dujon, B., et al. 2000. Genomic exploration of the hemiascomycetous yeasts: 1. A set of yeast species for molecular evolution studies. FEBS Lett. 487: $3-12$.

Stirling, C.J. and Hewitt, E.W. 1992. The Saccharomyces cerevisiae SEC65 gene encodes a component of the yeast signal recognition particle with homology to human SRP19. Nature 356: 534-537.

Strub, K., Fornallaz, M., and Bui, N. 1999. The Alu domain homolog of the yeast signal recognition particle consists of an Srp14p homodimer and a yeast-specific RNA structure. RNA 5: 1333-1347.

Ullu, E., Murphy, S., and Melli, M. 1982. Human 7SL RNA consists of a 140 nucleotide middle-repetitive sequence inserted in an Alu sequence. Cell 29: 195-202.

Willer, M., Jermy, A.J., Steel, G.J., Garside, H.J., Carter, S., and Stirling, C.J. 2003. An in vitro assay using overexpressed yeast SRP demonstrates that cotranslational translocation is dependent upon the J-domain of Sec63p. Biochemistry 42: 7171-7177.

Wolin, S.L. and Walter, P. 1989. Signal recognition particle mediates a transient elongation arrest of preprolactin in reticulocyte lysate. J. Cell Biol. 109: 2617-2622.

Wood, H., Luirink, J., and Tollervey, D. 1992. Evolutionary conserved nucleotides within the E. coli $4.5 \mathrm{~S}$ RNA are required for association with $\mathrm{p} 48$ in vitro and for optimal function in vivo. Nucleic Acids Res. 20: 5919-5925.

Zwieb, C. 1992. Recognition of a tetranucleotide loop of signal recognition particle RNA by protein SRP19. J. Biol. Chem. 267: 15650-15656.

Zwieb, C. and Eichler, J. 2001. Getting on target: The archaeal signal recognition particle. Archaea 1: 27-34. 



A PUBLICATION OF THE RNA SOCIETY

\section{Saccharomyces SRP RNA secondary structures: A conserved S-domain and extended Alu-domain}

ROB W. VAN NUES and JEREMY D. BROWN

RNA 2004 10: 75-89

References This article cites 48 articles, 21 of which can be accessed free at: http://rnajournal.cshlp.org/content/10/1/75.full.html\#ref-list-1

License

Email Alerting Receive free email alerts when new articles cite this article - sign up in the box at the Service top right corner of the article or click here.

To subscribe to $R N A$ go to:

http://rnajournal.cshlp.org/subscriptions 